\title{
Causes of and treatment options for dislocation following total hip arthroplasty (Review)
}

\author{
YIAN LU, HAIJUN XIAO and FENG XUE \\ Department of Orthopedics, Fengxian Central Hospital, Shanghai 201400, P.R. China
}

Received May 21, 2019; Accepted June 28, 2019

DOI: $10.3892 /$ etm.2019.7733

\begin{abstract}
The second most common complication following total hip arthroplasty (THA) is dislocation. The majority of dislocations occur early in the post-operative period and are due to either patient-associated or surgical factors. The patient-associated factors that have been implicated as causes of post-operative dislocation include previous surgery, lumbar spine fusion surgery and/or neurological impairment. The surgical factors include surgical approach, component orientation and prosthetic and/or bony impingement. In order to delineate the cause of the hip instability a thorough history and physical and a radiographic assessment (possibly including advanced imaging) needs to be performed. Approximately two thirds of cases are successfully treated; one third of cases will require surgical treatment (e.g., revision arthroplasty (including constrained liners, the use of elevated rim liners and dual mobility implants or trochanteric advancement). In this review, we discuss the causes leading to dislocation following THA and evaluate the different treatment options available.
\end{abstract}

\section{Contents}

1. Incidence of dislocation following total hip arthroplasty (THA) and evaluation of the unstable THA

2. Treatment options for dislocation following THA

3. Conclusions and future perspectives

1. Incidence of dislocation following total hip arthroplasty (THA) and evaluation of the unstable THA

The second most common complication following total hip arthroplasty (THA) is dislocation following aseptic loos-

Correspondence to: Dr Feng Xue, Department of Orthopedics, Fengxian Central Hospital, 9588 South Feng Road, Fengxian, Shanghai 201400, P.R. China

E-mail: xuefengmd333@163.com

Key words: dislocation, total hip arthroplasty, operative treatment, revision hip surgery, constrained liners ening, affecting up to $11 \%$ of patients following primary surgery (1-6). The majority of hip dislocations are posterior. In the study by Woolson and Rahimtoola, a dislocation rate of $3.2 \%$ was reported from 10,500 THAs performed; a variety various surgical approaches were included in that cohort (7). The dislocation rate is higher following revision surgery with rates as high as approximately $25 \%$ (8). The incidence in Italy has been reported to be similar with rates between 0.3 to $10 \%$ in primary THAs and up to $28 \%$ in revision THA (9). Sah and Esok also noted that the conversion of a hip hemiarthroplasty to a total hip replacement resulted in dislocations following the conversion procedures of $22 \%$ (10).

Rowan et al recently performed a literature search to assess historical perspectives and current strategies to prevent dislocation following primary THA (this study included 3,458 articles and included 154 in their analysis) (11). It has been demonstrated that a greater age, a body mass index $>30 \mathrm{~kg} / \mathrm{m}^{2}$, lumbosacral pathology, surgical experience, rheumatoid arthritis and femoral head size influences the rate of THA dislocation (12-14). Evidence regarding the effects of neuromuscular disease, sequelae of pediatric hip conditions and surgical approaches on THA instability has not been as conclusive as the risk factors for instability. It is clear that sex, simultaneous bilateral THA and restrictive post-operative precautions do not influence the rate of THA dislocation. Navigation, robotics, lipped liners and dual-mobility acetabular components may reduce dislocation rates (15). The risk of recurrent dislocation and the need for subsequent revision is also significant (16). In the study by Kotwal et al (16), the authors reported on 99 patients (101 hips) over a 6-year period that had a first dislocation of a primary THR; of these patients, 61 hips $(60.4 \%)$ had a repeat dislocated more than once and 47 hips (51\% in total) required revision surgery due to the instability. It has also been suggested that surgeon case volume has been identified as an important factor impacting post-operative outcomes in patients undergoing orthopedic surgery; however there has not been conclusive statistical analysis that it results in a 3 rate of hip dislocations (17). Dislocations occur most frequently within the first 3 months after surgery; up to $70 \%$ of dislocations occur within the first month (18); $66 \%$ of dislocations occurred within the first 5 weeks (19). Recurrent dislocations typically require additional surgery (20).

Risk factors. Prior hip surgery is a risk factor for dislocation following THA; prior hip surgery appears to be associated 
with a doubled risk of dislocation following THA $(21,22)$. Daly and Morrey reported a dislocation rate of $2.4 \%$ without previous hip surgery as compared to $4.8 \%$ for those with previous surgery (23). Fackler and Poss reported a dislocation rate of $5.5 \%$ in revision THA as compared to $1.8 \%$ in primary THA (24). The rate of recurrent dislocation can be as high, and can be 5 -fold greater in patients who have had previous surgery than in those who have not had previous surgery (25).

There does not appear to be any correlation between pre-operative diagnosis, including developmental dysplasia of the hip (DDH), and the risk of hip dislocation $(19,26)$. It is not clear whether sex is a risk factor for hip dislocation; in some studies, the female-to-male ratio was 2:1 $(21,19)$; however some other studies have report no differences between the sexes $(7,27)$. It also appears that the dislocation rate following THA performed for displaced femoral neck fracture has been improved with modern implants as long as the implants are properly positioned, particularly especially the acetabular component $(1,2,6,28)$.

A number of studies have been published on cerebral dysfunction (i.e., a state of confusion, history of excessive alcohol consumption, Parkinson's disease, or neuromuscular disorders) and the risk of dislocation following THA $(7,29,30)$. Several analyses have been performed on various patient characteristics (e.g., age, sex, height, weight, pre-operative diagnosis and cerebral dysfunction) and the rate of dislocation; the only variable associated with a higher dislocation rate was found to be cerebral dysfunction (7). Excessive alcoholic intake has also been associated with a dislocation rate as high as $23 \%$, as compared to a $5 \%$ dislocation rate among patients without such a history (27). A higher rate of dislocation has also been noted in patients with neuromuscular disorders or in patients with a confused mental state; post-operative delirium is also another risk factor (31). From a national inpatient sample analysis of patients with delirium $(n=13,551)$ and without delirium $(n=1,992,971)$ it was noted that there was an increase in the number of peri-operative complications, inducing dislocation following THA (31).

Hip range of motion may be a risk factor for dislocation with a greater risk of impingement and dislocation in those patients with a greater post-operative hip range of motion. Extremes in hip range of motion may cause hip impingment and/or stretching of the pseudocapsule, predisposing to late dislocations due to decreased soft tissue tension; however, the precise range of hip motion that could be considered to lead to an increased risk of dislocation has yet to be determined. In addition, there are some published case reports available on hip dislocation due to yoga (32), in theory due to extremes in hip range of motion.

Surgical factors. There has been much debate as to the differences in surgical approaches and the risk of dislocations following THA (33-36). Posterolateral or posterior surgical approaches have been shown to be associated with a higher dislocation rate than the anterior approach (21,37-40). Since many of the proponents of the anterior approach perform the surgery on a specific surgical table with the extremity fixed, the ability to carry out dynamic testing is lost. The majority of the proponents of the posterior approach carry out dynamic testing for hip stability and soft tissue tension across the hip (i.e., push-pull test). Tanino et al, from the study of 185 hips, noted that with a $32 \mathrm{~mm}$ metal femoral head, that an intraoperative stability test, particularly the IR angle, was a useful method to predict hip stability following THA (41). If a trochanteric osteotomy is performed, the risk of dislocation is increased, particularly if a nonunion develops (24). If there is a trochanteric nonunion with a $>1-\mathrm{cm}$ superior migration of the greater trochanter, there can then be up to a 6 -fold increase in hip instability (26). Some investigators have reported no significant differences in dislocation rates among various surgical approaches (19). A common surgical factor for dislocation is the malposition of the acetabular cup; either too vertical or improper anteversion or femoral component malorientation $(19,21,22,37,42)$. Excessive anteversion or retroversion of the femoral component can be a cause for THA instability. If the femoral component is overly anteverted, dislocation can occur when the hip is placed in extension and external rotation. If the femoral component is retroverted, posterior dislocation can occur when the hip when the hip is internally rotated (43). Acetabular component orientation is one of the most important surgical factors for THA stability $(21,22,24,42,44,45)$.

Without the use of robotics or computer -assisted navigation, the position of the patient on the operating room table is critical, as the guides used to assess the orientation of the acetabular component are based on it. Forward rotation of the pelvis during positioning in the lateral decubitus position can cause excessive retroversion of the acetabular component (26). Acetabular component orientation is critical to avoid cup-femoral component impingment and dislocation; the 'safe position' for the cup is noted to be $15 \pm 10^{\circ}$ anteversion, $40 \pm 10^{\circ}$ abduction (37). Dislocation rates as high as $6 \%$ have been reported when the acetabular component was inserted outside the safe position as compared with $1.5 \%$ when the acetabular component was inserted within this range (37). Others have noted that the safest range of acetabular cup positioning was $30-50^{\circ}$ of abduction and $20-40^{\circ}$ of anteversion, which enabled a stable hip to remain and allowed for a physiological range of motion (43). Excessive abduction of the acetabular component has been reported to be associated with $90 \%$ of dislocations following primary THAs (18). Acetabular components placed in a more horizontal (i.e., in an abduction angle less than 45 degrees) position resulted in lower rates of dislocation (46). Implant impingement (i.e., the femoral neck on the acetabular component or adjacent osteophytes) is another cause for THA dislocation. A reduction in femoral offset (i.e., shortening the distance between the greater trochanter and prosthetic head) increases the probability of hip impingment (i.e., levering the femoral prosthesis out of the acetabulum) and dislocation (47). Femoral offset also affects the efficiency of the abductors and the amount of force that can be generated across the hip joint and the soft tissue tension and the limb length (48). It has been reported that the greater trochanter was closer to the prosthetic head in patients who have had a dislocation (24). However, in some series, it was noted that the unstable hip was longer than the non-operated hip and this may be due issues of abductor laxity at surgery that were attempted to be rectified by making the limb longer (21).

A larger cross-sectional diameter of the femoral neck can lead to impingement of the neck onto the acetabular component (49). The design and diameter of the implant femoral neck 
influences the hip range of motion and implant femoral necks with a smaller anteroposterior diameter having a greater range of motion before impingement occurs as compared to larger cross-sectional diameter femoral necks (50).

Femoral head size is a factor in determining stability of the hip; 32-mm femoral heads instead of the 22-mm head size in the original Charnley total hip design was based on the theory that larger heads would reduce the rate of dislocation. However, a number of studies have reported no significant differences in dislocation rates among these 2 femoral head sizes $(21,24,45)$. Kelley et $\mathrm{al}$, in a prospective randomized study, reported a higher rate of dislocation in patients with 22-mm heads compared to those patients with a $28-\mathrm{mm}$ head, and the dislocation risk was further increased with larger-diameter acetabular components (51).

Evaluation of the unstable THA. There appears to be different causes for dislocations if they occur with 0-3 months from surgery, 4 months to 5 years post-operatively, and 5 or more years post-operatively (23). Early dislocations (within 0-3 months from surgery) typically occur due to a lack of mature scar tissue, a lack of soft tissue tension or patient factors and dislocations that occur later in the post-operative period (after 5 years post-operatively) are primarily due to component malposition and polyethylene wear (23).

A thorough physical examination and radiographic evaluation is essential in determining the direction and cause of the dislocation. An anterior dislocation is usually caused by extension and external rotation and a posterior dislocation is usually caused by flexion and internal rotation (26). In cases of late dislocation ( $>3$ months following surgery) a greater-than-expected range of internal and external rotation could be indicative of laxity of the pseudocapsule and a loss of soft tissue tension (26).

A radiographic evaluation of the femoral component should include the assessment of misalignments (i.e., excessive varus/valgus angulation), determination of the presence of osteolysis or loosening and the assessment of cortical integrity. It is important to assess the association of the greater trochanter with the femoral head in order to determine possible impingement and soft tissue tension. The version of the femoral component can be assessed using fluoroscopy or a CT scan $(9,24)$.

Radiographic assessment of the acetabular component should assess component position, the presence of osteolysis and/or component loosening. To calculate the acetabular cup abduction, an anteroposterior radiographic can be used and the abduction angle determined from the line drawn through both acetabular teardrops and a line drawn tangent to the face of the acetabulum; a cross-table lateral radiograph for the determination of flexion of the acetabular component is not accurate as the position of the cup in a cross-table lateral x-ray varies with the degree of flexion of the uninvolved hip $(21,43,52)$. 'Safe' ranges for acetabular component positioning (37) are $15 \pm 10^{\circ}$ anteversion and $40 \pm 10^{\circ}$ abduction. The version of the acetabulum can be most accurately evaluated by computerized axial tomography (CAT) (53). More recently, emerging research has questioned the previous characterization of an acetabular 'safe zone' and further identified lumbar spine disease and surgical fusion as significant risk factors for recurrent instability (54-59). From a systematic review with a meta-analysis (60), patients with a prior history of lumbar spinal fusion were shown to be at a significantly increased risk of having dislocations following THA (relative risk, 2.03) and revision (relative risk, 3.36). Patients with sagittal spinal deformity appear to be at a particularly high risk of THA instability due to postural compensation for abnormal spinal alignment (61); in a study of 139 THAs in 107 patients with sagittal spinal deformity, there was a THA dislocation rate of $8.0 \%$, with a revision rate of $5.8 \%$ for instability due to apparently a significantly higher spinopelvic tilt, T1-pelvic angle, and mismatch of lumbar lordosis and pelvic incidence (61). Salib et al noted that lumbar fusion involving the sacrum increased the risk of dislocation in primary THA, and using a case-control study design found that dislocation in the fusion group was $5.2 \%$ at 1 year versus $1.7 \%$ in the controls (62). King et al, using a Medicare database reported on the dislocation-free survival experience of patients with THA undergoing lumbar spine fusion (LSF) and compared this to similar patients not undergoing LSF. Of the 17,223 patients without a history of hip instability following THA, no increase in their instability rate was observed following lumbar fusion; however, their rate was statistically higher at $0.7 \%$ as compared to those who never had lumbar fusion at $0.4 \%$ (the total data pool included 863,182 patients who had not had a dislocation) (63). A Nationwide Readmissions Database was used to identify cases of elective primary THA over a 2-year period and all readmissions associated with dislocations were identified; this study consisted of 207,285 THA cases that were identified; of these 2,842 had dislocation-associated readmissions (1.4\%); it was noted that a history of spinal fusion was the most significant independent risk factor for dislocation within the first 6 months following THA (64). Esposito et al reported that from a consecutive series of 1,000 patients that underwent post-operative low-dose biplanar spine-to-ankle lateral radiographs in standing and sitting positions at 1 year following THA, 12 patients (1\% of all patients) experienced a hip dislocation and that these patients with fixed spinopelvic alignment from standing to sitting position were at a higher risk of suffering from hip dislocation (65). Malkani et al (66) published a study to determine whether the risk of dislocation and/or revision following THA is increased in patients with a history of prior lumbar fusion given the alterations in dynamic pelvic motion; they reviewed 62,387 patients from a Medicare data base and found that the prevalence of hip dislocation in patients with lumbar fusion prior to THA was $7.4 \%$ compared to $4.8 \%$ without fusion that was statistically significant $(\mathrm{P}<0.001)$.

Classification. There has been a proposed classification system for THA dislocation in order to direct treatment; however, this has not found widespread use (52). The classification is based on component position and soft tissue balance; however, when considering both patient and surgical factors for instability, this have not been useful. Commonly performed trochanteric osteotomy in the past with non-union and trochanteric escape are an infrequent problem and with modular implants more hips more frequently made longer than the native hip, this has made soft tissue balance less of a cause for instability. Patients that have multiple dislocations as compared to those who 
experienced only or two episodes of dislocation, naturally have a worse outcome; thus, it is important to identify the cause of the instability and intervene at an early stage (20).

\section{Treatment options for dislocation following THA}

Non-operative treatment. Dislocations that occur within the first 3 months post-operatively are managed by closed reduction; these are typically due to relaxed soft tissues and immature scar tissue, assuming there implants are properly positioned (23). The risk of redislocation can be as high as $33 \%$ due to the disruption of the forming soft tissue envelope; if the dislocation occurs after 5 weeks post-operatively, the redislocation can be as high as $60 \%$ (19).

Closed treatment for a first-time dislocation is usually successful in two-thirds of cases (21). Bracing or hip spica immobilization continued for 3-4 months following closed reduction for recurrent dislocation has been suggested; however, studies have noted that this is not effective $(18,52,67)$.

Surgical management. Revision surgery is necessary for those patients with persistent instability following non-operative management and for those who have component malposition; reoperation rates of $31-44 \%$ have been reported $(19,21,52,68)$. Capsular repair during revision can be effective (69).

Dislocations between 4 months and 5 years are usually due to component malposition, impingment or abductor mechanism dysfunction (uncommon due to the lack of trochanteric osteotomy today). In a prior series, component malposition (58\%) and failure of the abductor mechanism (42\%) were the most common causes of recurrent dislocation determined at the time of surgery (10).

Instability $>5$ years post-operatively is usually due to acetabular wear and is best addressed with acetabular revision. It is important to consider that there may be a lack of soft tissue tension due to inflammation from polyethylene debris or capsular stretching (23) and that stretching of the pseudocapsule over time due to extremes in motion lessens soft-tissue constraints and allows for dislocation (68). With the newer bearing material it has been reported that there is no difference in the revision rate amongst the 192,275 THAs included in the study from the Australian Orthopaedic Association National Joint Replacement Registry with 101,915 metal-on-cross-linked polyethylene or 30,256 ceramic-on-cross-linked polyethylene (CoXLPE), and 60,104 ceramic-on-ceramic bearing, as it appears that wear rate with these modern bearings is so similar, they are not a cause of late dislocation up to 13 years since surgery (70).

It is critical to identify the cause of the instability; few researchers have reported outcomes of reoperation for recurrent instability with long-term follow-up with some results noting a success rates of only $61 \%(23)$.

Surgical approach and method of closure for the prevention of dislocations. There has been much debate regarding the surgical approach and dislocation risk. Pellicci et al and others have purported that an enhanced posterior soft tissue repair performed through a posterior approach to the hip results in a reduced dislocation rate (71-73). This method of closure involves reconstructing the posterior soft tissue sleeve including the short tendinous external rotators, the posterior capsule, the quadratus femoris and tendinous insertion of the gluteus maximus. In a large series $(1,518)$ of THAs in which the anterolateral abductor split approach was used, a low (1\%) dislocation rate was reported (74). Traditionally, it had been recommended to have restricted mobilization following THAs to reduce the risk of dislocation and muscle detachment, including the use of an abduction pillow, particularly for patients that had a posterior approach. It has become clear that these post-operative restrictions are unnecessary and not supported by peer-reviewed publications; as the hospital stay has shortened, these restrictions have been reduced and there has been no increase in cases of early THA instability $(35,75)$. In addition, van der Weegen et al performed a prospective consecutive series of 1,049 primary THAs managed with minimal post-operative restrictions and compared the rate of instability to a prior consecutive series of cases from the same institution using a posterior approach and a traditional restrictive protocol; they found an instability rate of $1.6 \%$ in the minimal restrictive groups as compared to $2.5 \%$ in the traditional restrictive group, and they concluded that patients can be managed safely with minimal restrictions following posterior approach THA (75).

Trochanteric advancement. With modular implants, trochanteric osteotomy is not commonly performed, since if the hip needs be re-operated on and there is no impingement, the hip can be 'lengthened' and the offset increased by just using a longer modular head. If there is a monobloc femoral component and the implants are well aligned, a trochanteric advancement for the treatment of recurrent dislocation can be performed; it has been reported that a $76 \%$ success rate has been achieved using this strategy (76).

Elevated rim liners. There continues to be controversy as regards the use of elevated rim liners. In theory, elevated rim liners are used as their asymmetrical configuration provides added support in regions of greater instability if placed in the posterior-superior position when performing a posterior approach to the hip $(77,78)$ and low dislocation rates have been reported in both primary and revision cases. In a retrospective study of post-operative hip stability, Cobb et al reviewed 2,469 acetabular components with an elevated-rim liner (10 degrees of elevation) and 2,698 with a standard liner and found a significantly lower rate of dislocation among the elevated rim liner group at 2 years; a similar, non-significant trend was observed at 5 years (79). An updated review and meta-analysis of 8 studies that included 4,656 revision THAs noted that acetabular components with elevated rim liners were less likely to develop dislocation following revision THA (80). Others have argued that elevated liners create impingment, increased polyethylene wear debris and an increased rate of loosening due to the high torsional forces at the implant-bone interface imposed by the higher rotatory moment arm $(43,53,81)$.

Jumbo femoral heads. Due to improvements in polyethylene and femoral head materials, there has been a trend for the use of lager femoral heads to reduce the risk of instability (82-86). It has been reported that patients with large 
acetabular cups ( $>56 \mathrm{~mm}$ ) have an increased dislocation rate as compared to patients with smaller cups when using a $28 \mathrm{~mm}$ head (87). Larger femoral heads, as they must travel a greater excursion distance prior to dislocation, may reduce THA instability $(88,89)$. Larger heads (head diameter, 44-50 $\mathrm{mm}$ ) have been used for the treatment of patients with recurrent instability; in one study, at an average follow-up of 6.5 years, only 1 of the 12 patients treated had recurrent instability (90). It has been suggested that a multimodal protocol including patient education, the use of large femoral heads, posterior soft-tissue repair, and intraoperative adjustment of limb length and hip offset can reduce the dislocation rate $(91,92)$. The results from the study by Amado et al on 331 patients (mean age, 66 years; $68.8 \%$ females) revealed that the dislocation rate at 3 months was $0.60 \%$ and $0.90 \%$ at 12 months, and the authors recommended this type of protocol (91). Sikes et al reported on the results of a series of 41 patients at a high-risk for dislocation (52 hips) that were treated with large-diameter metal-on-metal bearings compared with a matched group treated with standard-size metal-on-polyethylene bearings, and found that the large-diameter femoral head group had no dislocations at a minimum follow-up of 24 months, whereas the standard-size group had 2 dislocations (93).

Constrained liners. Constrained liners are for patients with well-positioned implants and patient-related factor for instability or in cases with an incompetent abduction mechanism; these implants should only be used in salvage procedures in elderly and/or low-demand patients with hip instability (94-96). There have also been case reports of the mechanical failure of these devises (97).

In a study of 56 patients treated surgically for recurrent dislocations (mean dislocations, 6; mean previous procedures, 3), Goetz et al reported only 2 subsequent dislocations (4\%) (98). In another series, 101 constrained acetabular components were implanted for recurrent dislocation, intraoperative instability, or neurological impairment and there were only 4 cases (4\%) of recurrent dislocation in the group at an average follow-up or approximately 5 years (98). Jones published a systematic review of the literature of published evidence on the results of constrained liners; of the 38 studies included is his study, of a total of 2,852 constrained liners with a mean follow-up 4.3 years (range, $0.8-20$ years), the results noted a mean dislocation and/or constrained failure rate of $11.4 \%$ (95). Without longer-term follow-up studies on these implants, it is probable that the increased loosening ensues due to the constraint of the liner, which limits the longevity of the implants; thus, these implants should only be used for patients with limited life expectancy, low functional demands, and for whom all other possible treatments have failed or been deemed inappropriate. From the Australian Orthopaedic Association National Joint Replacement Registry, data from 9,509 THA first-revision procedures and 700 constrained components were reported; constrained components had a significantly higher revision rate after 3 months when large-head metal-on-metal components were used and constrained components had a higher second revision rate for further dislocation after 9 months. These authors supported the theory of reduced implant longevity with these devices; however, they noted that these devices may be used in more difficult situations with unstable hips (99).
Bipolar and tripolar prostheses; resection athroplasty and dual-mobility bearings. Bipolar hip arthroplasty has been proposed as a method of treatment for recurrent dislocations; however, this method is no longer preferred. Currently, although this method has been reported to prevent redislocations in $81 \%$ of hips treated in this manner for recurrent dislocation, a significant number of patients require further surgeries and it should be reserved for a small number of patients who have recurrent instability, when all other operative options are no longer plausible (100).

A tripolar hip replacement for recurrent prosthetic dislocation has been advocated by Grigoris et al; in their small series of only 8 patients with recurrent instability, the authors inserted a large-diameter acetabular cup and a bipolar femoral head sized to the approximate diameter of the normal hip with all of the patients in this series achieved stability at an average follow up of 4.2 years (8). In a small percentage of patients in which stability cannot be achieved despite multiple surgical procedures, a resection arthroplasty may be a last resort option.

Dual mobility (DM) bearings have been more recently introduced in patients at a high risk of suffering from dislocations $(101,102)$. A retrospective review of a consecutive series of DM THAs performed between 2010 and 2014 on 151 patients deemed to be at a high risk of suffering from dislocations reported a dislocation in only a single patient (103). The authors did express concern that longer follow-up is needed to confirm the durability of these reconstructions. In a previous systematic review and meta-analyses (104), which included 11 of 677 studies (9 comparative studies and 2 randomized controlled trials) ( $n=4,084$ patients) that met the inclusion criteria, dual mobility THA ( $n=1,068$ patients), standard THA ( $n=2,568$ patients), big head THA ( $n=378$ patients) and constrained THA ( $n=70$ patients), it was noted that the risk of revision and dislocation of dual mobility hips was significantly lower compared to standard THA bearing and there was no statistically significant risk of having revision or dislocations when compared to large femoral head or conventional THA, albeit the follow-up was only 5 years or less. Another study on patients with recurrent dislocations (105) reported on the short-term results of 40 patients with an average 3 -year follow-up who had undergone first-time revision for instability; recurrent dislocation was observed in only 2 patients (5\%). In another systematic review on the rate of dislocation following the use of dual mobility (106), in a total of 17,908 primary and revision THAs from 59 studies, a mean rate of dislocation of $0.9 \%$ was reported in the primary THA group, and $3.0 \%$ in the revision THA group; again these authors noted concerns regarding the long-term results and possible implant failures of these implants. Brüggemann et al reported on their results of cementing a dual mobility cup into a porous titanium shell in 184 hips (184 patients) following acetabular revision surgery and reported a reduced risk of dislocation following acetabular revision surgery without jeopardizing overall cup survival, and without enhancing tantalum release at a mean of an approximately 5-year follow-up (107). Chalmers et al also reported similarly good results in a small series of 18 cases using a similar technique (108). Hwang et al in their series of 167 hips in 165 patients with femoral neck fractures 
and using a posterolateral approach, reported only $4(2.3 \%)$ dislocations at a mean time of dislocation of 30.5 days post-operatively (109).

Ischiofemoral hip ligament and Achilles tendon allograft reconstructions. If the implants are well aligned, it has been reported that the reconstruction of the ischiofemoral ligament of the hip may prevent recurrent posterior dislocations. Only small-case series have been published using this technique in only 5 patients; however, no recurrent dislocations were reported at a mean follow-up of 47 months (110). A similar case report (111) using an Achilles allograft sling to improve hip stability in 8 patients has also been reported.

\section{Conclusions and future perspectives}

Dislocation is a major complication of THAs, and the causes include patient-derived factors, surgical factors, or both. It is imperative to determine the cause of the instability through a complete patient and radiographic evaluation (e.g., component malposition, insufficient soft tissue tension and impingement). The majority of dislocations can be treated successfully in a closed manner as they occur early after surgery. For patients who suffer from recurrent dislocations, reoperation will normally be required, with optimal results being obtained if the cause is clearly identified. Surgical treatment for recurrent dislocations includes trochanteric advancement, revision arthroplasty, or the use of constrained components.

\section{Acknowledgements}

Not applicable.

\section{Funding}

No funding was received.

\section{Availability of data and materials}

Not applicable.

\section{Authors' contributions}

YL conceived this review article and HX and FX were responsible for the collection and assembly of the articles/published data, for inclusion and interpretation in this review. All authors were involved in the writing of the manuscript. All authors have read and approved the final manuscript.

\section{Ethics approval and consent to participate}

Not applicable.

\section{Patient consent for publication}

Not applicable.

\section{Competing interests}

The authors declare that they have no competing interests.

\section{References}

1. Khan M, Della Valle CJ, Jacofsky DJ, Meneghini RM and Haddad FS: Early postoperative complications after total hip arthroplasty: Current strategies for prevention and treatment. Instr Course Lect 64: 337-346, 2015.

2. Dargel J, Oppermann J, Brüggemann G-P and Eysel P: Dislocation following total hip replacement. Dtsch Arztebl Int 111: 884-890, 2014.

3. D'Angelo F, Murena L, Zatti G and Cherubino P: The unstable total hip replacement. Indian J Orthop 42: 252-259, 2008.

4. Dawson-Amoah K, Raszewski J, Duplantier N and Waddell BS: Dislocation of the Hip: A Review of Types, Causes, and Treatment. Ochsner J 18: 242-252, 2018.

5. Bauer T and Resnick L: Preventing and Managing Post-THA Hip Dislocations. JBJS Case Connect 7: e11, 2017.

6. Berend KR, Sporer SM, Sierra RJ, Glassman AH and Morris MJ: Achieving stability and lower limb length in total hip arthroplasty. Instr Course Lect 60: 229-246, 2011.

7. Woolson ST and Rahimtoola ZO: Risk factors for dislocation during the first 3 months after primary total hip replacement. J Arthroplasty 14: 662-668, 1999.

8. Grigoris P, Grecula MJ and Amstutz HC: Tripolar hip replacement for recurrent prosthetic dislocation. Clin Orthop Relat Res \&NA; 148-155, 1994.

9. Falez F, Papalia M, Favetti F, Panegrossi G, Casella F and Mazzotta G: Total hip arthroplasty instability in Italy. Int Orthop 41: 635-644, 2017.

10. Sah AP and Estok DM II: Dislocation rate after conversion from hip hemiarthroplasty to total hip arthroplasty. J Bone Joint Surg Am 90: 506-516, 2008.

11. Rowan FE, Benjamin B, Pietrak JR and Haddad FS: Prevention of Dislocation After Total Hip Arthroplasty. J Arthroplasty 33: 1316-1324, 2018

12. Bookman JS, Schwarzkopf R, Rathod P, Iorio $R$ and Deshmukh AJ: Obesity: The Modifiable Risk Factor in Total Joint Arthroplasty. Orthop Clin North Am 49: 291-296, 2018

13. Annan J, Clement N, Macpherson GJ, Brenkel IJ, Ballantyne JA and Dunstan E: Body mass index, hip function and surgeon volume are independent predictors of dislocation: An analysis of 4334 total hip replacements. Eur J Orthop Surg Traumatol 28: 899-905, 2018.

14. Ravi B, Croxford R, Hollands S, Paterson JM, Bogoch E, Kreder $\mathrm{H}$ and Hawker GA: Increased risk of complications following total joint arthroplasty in patients with rheumatoid arthritis. Arthritis Rheumatol 66: 254-263, 2014.

15. Perets I, Walsh JP, Close MR, Mu BH, Yuen LC and Domb BG: Robot-assisted total hip arthroplasty: Clinical outcomes and complication rate. Int J Med Robot 14: e1912, 2018.

16. Kotwal RS, Ganapathi M, John A, Maheson M and Jones SA: Outcome of treatment for dislocation after primary total hip replacement. J Bone Joint Surg Br 91: 321-326, 2009.

17. Malik AT, Jain N, Scharschmidt TJ, Li M, Glassman AH and Khan SN: Does Surgeon Volume Affect Outcomes Following Primary Total Hip Arthroplasty? A Systematic Review. J Arthroplasty 33: 3329-3342, 2018.

18. Williams JF, Gottesman MJ and Mallory TH: Dislocation after total hip arthroplasty. Treatment with an above-knee hip spica cast. Clin Orthop Relat Res (171): 53-58, 1982.

19. Ali Khan MA, Brakenbury PH and Reynolds IS: Dislocation following total hip replacement. J Bone Joint Surg Br 63-B: 214-218, 1981.

20. Chandler RW, Dorr LD and Perry J: The functional cost of dislocation following total hip arthroplasty. Clin Orthop Relat Res \&NA; 168-172, 1982.

21. Woo RY and Morrey BF: Dislocations after total hip arthroplasty. J Bone Joint Surg Am 64: 1295-1306, 1982.

22. Eftekhar NS: Dislocation and instability complicating low friction arthroplasty of the hip joint. 1976. Clin Orthop Relat Res 453: 1-5, 2006.

23. Daly PJ and Morrey BF: Operative correction of an unstable total hip arthroplasty. J Bone Joint Surg Am 74: 1334-1343, 1992.

24. Fackler CD and Poss R: Dislocation in total hip arthroplasties. Clin Orthop Relat Res (151): 169-178, 1980.

25. Joshi A, Lee CM, Markovic L, Vlatis G and Murphy JC: Prognosis of dislocation after total hip arthroplasty. J Arthroplasty 13: 17-21, 1998.

26. Morrey BF: Instability after total hip arthroplasty. Orthop Clin North Am 23: 237-248, 1992. 
27. Paterno SA, Lachiewicz PF and Kelley SS: The influence of patient-related factors and the position of the acetabular component on the rate of dislocation after total hip replacement. J Bone Joint Surg Am 79: 1202-1210, 1997.

28. Noticewala M, Murtaugh TS, Danoff J, Cunn GJ, Shah RP and Geller J: Has the risk of dislocation after total hip arthroplasty performed for displaced femoral neck fracture improved with modern implants? J Clin Orthop Trauma 9: 281-284, 2018.

29. Kheir MM, Kheir YNP, Tan TL, Ackerman CT, Rondon AJ and Chen AF: Increased Complications for Schizophrenia and Bipolar Disorder Patients Undergoing Total Joint Arthroplasty. J Arthroplasty 33: 1462-1466, 2018

30. Rondon AJ, Tan TL, Schlitt PK, Greenky MR, Phillips JL and Purtill JJ: Total Joint Arthroplasty in Patients With Parkinson's Disease: Survivorship, Outcomes, and Reasons for Failure. J Arthroplasty 33: 1028-1032, 2018.

31. Aziz KT, Best MJ, Naseer Z, Skolasky RL, Ponnusamy KE, Sterling RS and Khanuja HS: The Association of Delirium with Perioperative Complications in Primary Elective Total Hip Arthroplasty. Clin Orthop Surg 10: 286-291, 2018.

32. Adrados M, Myhre LA and Rubin LE: Late total hip arthroplasty dislocation due to yoga. Arthroplast Today 4: 180-183, 2018.

33. Talia AJ, Coetzee C, Tirosh O and Tran P: Comparison of outcome measures and complication rates following three different approaches for primary total hip arthroplasty: A pragmatic randomised controlled trial. Trials 19: 13, 2018.

34. Miller LE, Gondusky JS, Bhattacharyya S, Kamath AF, Boettner F and Wright J: Does Surgical Approach Affect Outcomes in Total Hip Arthroplasty Through 90 Days of Follow-Up? A Systematic Review With Meta-Analysis. J Arthroplasty 33: 1296-1302, 2018

35. Seagrave KG, Troelsen A, Madsen BG, Husted H, Kallemose T and Gromov K: Can Surgeons Reduce the Risk for Dislocation After Primary Total Hip Arthroplasty Performed Using the Posterolateral Approach? J Arthroplasty 32: 3141-3146, 2017.

36. Meermans G, Konan S, Das R, Volpin A and Haddad FS: The direct anterior approach in total hip arthroplasty: A systematic review of the literature. Bone Joint J 99-B: 732-740, 2017.

37. Lewinnek GE, Lewis JL, Tarr R, Compere CL and Zimmerman JR: Dislocations after total hip-replacement arthroplasties. J Bone Joint Surg Am 60: 217-220, 1978.

38. Kanda A, Kaneko K, Obayashi O, Mogami A and Morohashi I: Preservation of the articular capsule and short lateral rotator in direct anterior approach to total hip arthroplasty. Eur J Orthop Surg Traumatol 28: 1111-1116, 2018.

39. Miller LE, Gondusky JS, Kamath AF, Boettner F, Wright J and Bhattacharyya S: Influence of surgical approach on complication risk in primary total hip arthroplasty. Acta Orthop 89: 289-294, 2018.

40. Ponzio DY, Poultsides LA, Salvatore A, Lee YY, Memtsoudis SG and Alexiades MM: In-Hospital Morbidity and Postoperative Revisions After Direct Anterior vs Posterior Total Hip Arthroplasty. J Arthroplasty 33: 1421-1425.e1, 2018.

41. Tanino H, Sato T, Nishida Y, Mitsutake R and Ito H: Hip stability after total hip arthroplasty predicted by intraoperative stability test and range of motion: A cross-sectional study. BMC Musculoskelet Disord 19: 373, 2018

42. Carlsson AS and Gentz CF: Postoperative dislocation in the Charnley and Brunswik total hip arthroplasty. Clin Orthop Relat Res 125: 177-182, 1977

43. McCollum DE and Gray WJ: Dislocation after total hip arthroplasty. Causes and prevention. Clin Orthop Relat Res 261: $159-170,1990$

44. Etienne A, Cupic Z and Charnley J: Postoperative dislocation after Charnley low-friction arthroplasty. Clin Orthop Relat Res 132: 19-23, 1978.

45. Ritter MA: Dislocation and subluxation of the total hip replacement. Clin Orthop Relat Res 121: 92-94, 1976.

46. Kennedy JG, Rogers WB, Soffe KE, Sullivan RJ, Griffen DG and Sheehan LJ: Effect of acetabular component orientation on recurrent dislocation, pelvic osteolysis, polyethylene wear, and component migration. J Arthroplasty 13: 530-534, 1998

47. Geier A, Kluess D, Grawe R, Herrmann S, D'Lima D, Woernle C and Bader R: Dynamical analysis of dislocation-associated factors in total hip replacements by hardware-in-the-loop simulation. J Orthop Res 35: 2557-2566, 2017.

48. Sculco PK, Cottino U, Abdel MP and Sierra RJ: Avoiding Hip Instability and Limb Length Discrepancy After Total Hip Arthroplasty. Orthop Clin North Am 47: 327-334, 2016.
49. Barrack RL, Butler RA, Laster DR and Andrews P: Stem design and dislocation after revision total hip arthroplasty: Clinical results and computer modeling. J Arthroplasty 16 (Suppl 1): 8-12, 2001.

50. Kummer FJ, Shah S, Iyer S and DiCesare PE: The effect of acetabular cup orientations on limiting hip rotation. J Arthroplasty 14: 509-513, 1999.

51. Kelley SS, Lachiewicz PF, Hickman JM and Paterno SM Relationship of femoral head and acetabular size to the prevalence of dislocation. Clin Orthop Relat Res 355: 163-170, 1998.

52. Dorr LD, Wolf AW, Chandler R and Conaty JP: Classification and treatment of dislocations of total hip arthroplasty. Clin Orthop Relat Res 173: 151-158, 1983.

53. Murray DW: The definition and measurement of acetabular orientation. J Bone Joint Surg Br 75: 228-232, 1993.

54. Meneghini RM: Investigation of the Unstable Total Hip Arthroplasty. J Arthroplasty 33: 1325-1327, 2018.

55. Cho YJ, Lee JH, Shin SJ and Kang KC: Recurrent Hip Dislocation Following Total Hip Arthroplasty: Treatment with Sagittal Spinal Deformity Correction: A Case Report. JBJS Case Connect 7: e14, 2017.

56. Lazennec JY, Thauront F, Robbins CB and Pour AE: Acetabular and Femoral Anteversions in Standing Position are Outside the Proposed Safe Zone After Total Hip Arthroplasty. J Arthroplasty 32: 3550-3556, 2017.

57. Fessy MH, Putman S, Viste A, Isida R, Ramdane N, Ferreira A, Leglise A, Rubens-Duval B, Bonin N, Bonnomet F, et al; SFHG: What are the risk factors for dislocation in primary total hip arthroplasty? A multicenter case-control study of 128 unstable and 438 stable hips. Orthop Traumatol Surg Res 103: 663-668, 2017.

58. Reina N, Putman S, Desmarchelier R, Sari Ali E, Chiron P, Ollivier M, Jenny JY, Waast D, Mabit C, de Thomasson E, et al; SFHG: Can a target zone safer than Lewinnek's safe zone be defined to prevent instability of total hip arthroplasties? Case-control study of 56 dislocated THA and 93 matched controls. Orthop Traumatol Surg Res 103: 657-661, 2017.

59. Lazennec JY, Clark IC, Folinais D, Tahar IN and Pour AE: What is the Impact of a Spinal Fusion on Acetabular Implant Orientation in Functional Standing and Sitting Positions? J Arthroplasty 32: 3184-3190, 2017.

60. An VVG, Phan K, Sivakumar BS, Mobbs RJ and Bruce WJ: Prior Lumbar Spinal Fusion is Associated With an Increased Risk of Dislocation and Revision in Total Hip Arthroplasty: A Meta-Analysis. J Arthroplasty 33: 297-300, 2018.

61. DelSole EM, Vigdorchik JM, Schwarzkopf R, Errico TJ and Buckland AJ: Total Hip Arthroplasty in the Spinal Deformity Population: Does Degree of Sagittal Deformity Affect Rates of Safe Zone Placement, Instability, or Revision? J Arthroplasty 32: 1910-1917, 2017.

62. Salib CG, Reina N, Perry KI, Taunton MJ, Berry DJ and Abdel MP: Lumbar fusion involving the sacrum increases dislocation risk in primary total hip arthroplasty. Bone Joint J 101-B: 198-206, 2019.

63. King CA, Landy DC, Martell JM, Luu HH, Shi LL and Lee MJ: Time to Dislocation Analysis of Lumbar Spine Fusion Following Total Hip Arthroplasty: Breaking Up a Happy Home. J Arthroplasty 33: 3768-3772, 2018.

64. Gausden EB, Parhar HS, Popper JE, Sculco PK and Rush BNM: Risk Factors for Early Dislocation Following Primary Elective Total Hip Arthroplasty. J Arthroplasty 33: 1567-1571.e2, 2018.

65. Esposito CI, Carroll KM, Sculco PK, Padgett DE, Jerabek SA and Mayman DJ: Total Hip Arthroplasty Patients With Fixed Spinopelvic Alignment Are at Higher Risk of Hip Dislocation. J Arthroplasty 33: 1449-1454, 2018.

66. Malkani AL, Garber AT, Ong KL, Dimar JR, Baykal D, Glassman SD, Cochran AR and Berry DJ: Total Hip Arthroplasty in Patients With Previous Lumbar Fusion Surgery: Are There More Dislocations and Revisions? J Arthroplasty 33: 1189-1193, 2018.

67. Turner RS: Postoperative total hip prosthetic femoral head dislocations. Incidence, etiologic factors, and management. Clin Orthop Relat Res 301: 196-204, 1994.

68. Coventry MB: Late dislocations in patients with Charnley total hip arthroplasty. J Bone Joint Surg Am 67: 832-841, 1985.

69. Jurkutat J, Zajonz D, Sommer G, Schleifenbaum S, Möbius R, Grunert R, Hammer N and Prietzel T: The impact of capsular repair on the risk for dislocation after revision total hip arthroplasty - a retrospective cohort-study of 259 cases. BMC Musculoskelet Disord 19: 314, 2018 
70. Shah SM, Walter WL, Tai SM, Lorimer MF and de Steiger RN Late Dislocations After Total Hip Arthroplasty: Is the Bearing a Factor? J Arthroplasty 32: 2852-2856, 2017.

71.Pellicci PM, Bostrom M and Poss R: Posterior approach to total hip replacement using enhanced posterior soft tissue repair. Clin Orthop Relat Res 355: 224-228, 1998.

72. Takao M, Otake Y, Fukuda N, Sato Y, Armand M and Sugano N: The Posterior Capsular Ligamentous Complex Contributes to Hip Joint Stability in Distraction. J Arthroplasty 33: 919-924, 2018.

73.Zhou Y, Cao S, Li L, Narava M, Fu Q and Qian Q: Is soft tissue repair a right choice to avoid early dislocation after THA in posterior approach? BMC Surg 17: 60, 2017.

74. Mallory TH, Lombardi AV Jr, Fada RA, Herrington SM and Eberle RW: Dislocation after total hip arthroplasty using the anterolateral abductor split approach. Clin Orthop Relat Res 358: 166-172, 1999.

75. van der Weegen W, Kornuijt A, Das D, Vos R and Sijbesma T: It is safe to use minimal restrictions following posterior approach total hip arthroplasty: Results from a large cohort study. Hip Int: Jan 10, 2019 (Epub ahead of print).

76. Kaplan SJ, Thomas WH and Poss R: Trochanteric advancement for recurrent dislocation after total hip arthroplasty. J Arthroplasty 2: 119-124, 1987

77. McConway J, O'Brien S, Doran E, Archbold P and Beverland D: The use of a posterior lip augmentation device for a revision of recurrent dislocation after primary cemented Charnley/Charnley Elite total hip replacement: Results at a mean follow-up of six years and nine months. J Bone Joint Surg Br 89: 1581-1585, 2007.

78. Hoggett L, Cross C and Helm T: Experience of the posterior lip augmentation device in a regional hip arthroplasty unit as a treatment for recurrent dislocation. J Orthop 14: 512-514, 2017.

79. Cobb TK, Morrey BF and Ilstrup DM: The elevated-rim acetabular liner in total hip arthroplasty: Relationship to postoperative dislocation. J Bone Joint Surg Am 78: 80-86, 1996.

80. Guo L, Yang Y, An B, Yang Y, Shi L, Han X and Gao S: Risk factors for dislocation after revision total hip arthroplasty: A systematic review and meta-analysis. Int J Surg 38: 123-129, 2017.

81. Krushell RJ, Burke DW and Harris WH: Elevated-rim acetabular components. Effect on range of motion and stability in total hip arthroplasty. J Arthroplasty 6 (Suppl): S53-58, 1991.

82. Ho KWK, Whitwell GS and Young SK: Reducing the rate of early primary hip dislocation by combining a change in surgical technique and an increase in femoral head diameter to $36 \mathrm{~mm}$. Arch Orthop Trauma Surg 132: 1031-1036, 2012.

83. Amlie E, Høvik $\varnothing$ and Reikerås O: Dislocation after total hip arthroplasty with 28 and 32-mm femoral head. J Orthop Traumatol 11: 111-115, 2010

84. Stroh DA, Issa K, Johnson AJ, Delanois RE and Mont MA Reduced dislocation rates and excellent functional outcomes with large-diameter femoral heads. J Arthroplasty 28: 1415-1420, 2013.

85. Lachiewicz PF and Soileau ES: Low early and late dislocation rates with 36- and 40-mm heads in patients at high risk for dislocation. Clin Orthop Relat Res 471: 439-443, 2013.

86. Bistolfi A, Crova M, Rosso F, Titolo P, Ventura S and Massazza G: Dislocation rate after hip arthroplasty within the first postoperative year: $36 \mathrm{~mm}$ versus $28 \mathrm{~mm}$ femoral heads. Hip Int 21: 559-564, 2011.

87.Peter R, Lübbeke A, Stern R and Hoffmeyer P: Cup size and risk of dislocation after primary total hip arthroplasty. J Arthroplasty 26: 1305-1309, 2011.

88. Tsikandylakis G, Mohaddes M, Cnudde P, Eskelinen A, Kärrholm $\mathrm{J}$ and Rolfson $\mathrm{O}$ : Head size in primary total hip arthroplasty. EFORT Open Rev 3: 225-231, 2018.

89. Waddell BS, Koch C, Trivellas M, Burket JC, Wright T and Padgett D: Have large femoral heads reduced prosthetic impingement in total hip arthroplasty? Hip Int 29: 83-88, 2019.

90. Beaulé PE, Schmalzried TP, Udomkiat P and Amstutz HC: Jumbo femoral head for the treatment of recurrent dislocation following total hip replacement. J Bone Joint Surg Am 84: 256-263, 2002.

91. Amado O, Bautista M, Moore J, Bonilla G, Jimenez N and Llinás A: A multimodal approach prevents instability after total hip arthroplasty: A 1 year follow-up prospective study. J Clin Orthop Trauma 9: 137-141, 2018.
92. Jinno T, Koga D, Asou Y, Morita S, Okawa A and Muneta T: Intraoperative evaluation of the effects of femoral component offset and head size on joint stability in total hip arthroplasty. J Orthop Surg (Hong Kong) 25: 2309499016684298, 2017.

93. Sikes CV, Lai LP, Schreiber M, Mont MA, Jinnah RH and Seyler TM: Instability after total hip arthroplasty: Treatment with large femoral heads vs constrained liners. J Arthroplasty 23 (Suppl): 59-63, 2008.

94. Van der Merwe JM: Comprehensive Review of Current Constraining Devices in Total Hip Arthroplasty. J Am Acad Orthop Surg 26: 479-488, 2018

95. Jones SA: Constrained Acetabular Liners. J Arthroplasty 33: $1331-1336,2018$

96. Rady AE, Asal MK and Bassiony AA: The use of a constrained cementless acetabular component for instability in total hip replacement. Hip Int 20: 434-439, 2010

97. Arthur JA, Amanatullah DF, Kennedy GD and Di Cesare PE: Failure of a constrained acetabular liner without reinforcement ring disruption. Am J Orthop (Belle Mead NJ) 42: 566-568, 2013.

98. Goetz DD, Capello WN, Callaghan JJ, Brown TD and Johnston RC: Salvage of a recurrently dislocating total hip prosthesis with use of a constrained acetabular component. A retrospective analysis of fifty-six cases. J Bone Joint Surg Am 80: 502-509, 1998

99. Lewis PL, Graves SE, de Steiger RN and Cuthbert AR: Constrained Acetabular Components Used in Revision Total Hip Arthroplasty: A Registry Analysis. J Arthroplasty 32: 3102-3107, 2017

100. Parvizi J and Morrey BF: Bipolar hip arthroplasty as a salvage treatment for instability of the hip. J Bone Joint Surg Am 82: 1132-1139, 2000.

101. Bertram HM III, Bertram ME, Scholl L, Bhowmik-Stoke M and Manley MT: Capsular Sparing Total Hip Replacement Technique Applied with a Dual-mobility Cup to Reduce Dislocations. Surg Technol Int 33: 289-293, 2018.

102. Elbuluk AM, Slover J, Anoushiravani AA, Schwarzkopf R, Eftekhary N and Vigdorchik JM: The cost-effectiveness of dual mobility in a spinal deformity population with high risk of dislocation: A computer-based model. Bone Joint J 100-B 1297-1302, 2018.

103. Jones CW, De Martino I, D'Apolito R, Nocon AA, Sculco PK and Sculco TP: The use of dual-mobility bearings in patients at high risk of dislocation. Bone Joint J 101-B (1_Supple_A): 41-45, 2019.

104. Pituckanotai K, Arirachakaran A, Tuchinda H, Putananon C, Nualsalee N, Setrkraising K and Kongtharvonskul J: Risk of revision and dislocation in single, dual mobility and large femoral head total hip arthroplasty: Systematic review and network meta-analysis. Eur J Orthop Surg Traumatol 28: 445-455, 2018

105. Lange JK, Spiro SK and Westrich GH: Utilizing Dual Mobility Components for First-Time Revision Total Hip Arthroplasty for Instability. J Arthroplasty 33: 505-509, 2018.

106. De Martino I, D'Apolito R, Soranoglou VG, Poultsides LA, Sculco PK and Sculco TP: Dislocation following total hip arthroplasty using dual mobility acetabular components: A systematic review. Bone Joint J 99-B (A Suppl 1): 18-24, 2017.

107. Brüggemann A, Mallmin H and Hailer NP: Do dual-mobility cups cemented into porous tantalum shells reduce the risk of dislocation after revision surgery? Acta Orthop 89: 156-162, 2018.

108. Chalmers BP, Ledford CK, Taunton MJ, Sierra RJ, Lewallen DG and Trousdale RT: Cementation of a Dual Mobility Construct in Recurrently Dislocating and High Risk Patients Undergoing Revision Total Arthroplasty. J Arthroplasty 33: 1501-1506, 2018.

109. Hwang J-H, Kim S-M, Oh K-J and Kim Y: Dislocations after use of dual-mobility cups in cementless primary total hip arthroplasty: Prospective multicentre series. Int Orthop 42: 761-767, 2018.

110. Namazie MRBM and Hadlow AT: Ischiofemoral hip ligament reconstructions for recurrent posterior total hip joint dislocations. J Orthop 15: 913-916, 2018.

111. Van Warmerdam JM, McGann WA, Donnelly JR, Kim J and Welch RB: Achilles allograft reconstruction for recurrent dislocation in total hip arthroplasty. J Arthroplasty 26: 941-948, 2011. 